\title{
The effect of oral gavage (force-feeding) administration of fenugreek seeds (Trigonella foenum-graecum L.) on biochemical and neurobehavioural parameters in male Wistar rats
}

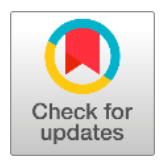

\author{
Faiza Rouag $^{\text {(iD) | Samir Djemli }}{ }^{\text {** }}$ (D) | Mabrouk Boussena ${ }^{\text {iD }}$ | Rouya Memouni ${ }^{\text {(iD }}$ | \\ Ines Refes $^{\text {a }}$ | Habiba Ferhati ${ }^{\text {iD }}$ | Abdelkrim Tahraoui
}

Applied Neuroendocrinology Laboratory, Department of Biology, Faculty of Sciences,Badji Mokhtar AnnabaUniversity, Algeria.

Corresponding author: s_djemli@yahoo.fr

\begin{abstract}
This study aims to evaluate the effect of fenugreek on biochemical parameters, body weight, and the behavior of male Wistar rats. The purpose of administering the aqueous extract of fenugreek seeds (Trigonella foenum-graecum $\mathrm{L}$ ) for 30 successive days by oral gavage (force-feeding) at a dose of $250 \mathrm{~g} /$ I of water is intended to assess, on the one hand, the neurobehavioural effects and 'on the other hand its effect on some biochemical parameters (glycemia and lipid balance) as well as weight. The behavioral tests performed are the Light/Dark Box tests (LDB) and the Elevated Plus Maze test (EPM). This work indicated that the consumption of the aqueous extract of the seeds of fenugreek is beneficial to stimulate appetite and gain weight, thus decreasing the level of total cholesterol, triglycerides, LDL-C, and a significant increase in $\mathrm{HDL}-\mathrm{C}$, also a reduction in blood sugar and a decrease in anxiety.
\end{abstract}

Keywords anxiety, blood sugar, fenugreek, weight, Wistar rats

\section{Introduction}

Faced with the expansion of diseases for which the coverage is high, the World Health Organization (WHO) has encouraged ethnobotanical studies and pharmaceutical research to innovate herbal medicines to promote their optimal uses in the field. Treatment of certain pathologies (Hamden et al 2011; Ghourri et al 2013). Trigonella foenumgraecum L. From the Arabic name, Helba is an annual herb known as fenugreek. (Talip et al 2011). It comes from foenum-graecum meaning Greek hay which is a dried herb to be used as fodder in the past (Ionescu and Roman 2013). Fenugreek is widely distributed. Regions of the world Europe, North Africa, Asia, Argentina, Canada, America, Australia. It has antioxidant and antibacterial activity and is known for its hypoglycaemic, hypocholesterolemia, and anti-inflammatory effects (Moradikor et al 2013). Its use is highly recommended, generally in cases of lack of appetite when preparing food (with rice in Iran, cheese aroma in Switzer moor) (Harchane et al 2012).

This work is part of a study on the research and development of plants of medicinal and therapeutic interest. It is based on the study of the effect of the aqueous extract of the seeds of fenugreek, used in traditional medicine on weight gain, on the improvement of several biochemical plasma parameters such; Blood sugar levels, cholesterol, triglycerides, HDL-cholesterol, and LDL-cholesterol on neurobehaviour in male Wistar rats.

\section{Materials and Methods}

\subsection{Biological materials}

Wistar male rats weighing $200 \pm 5 \mathrm{~g}$ were obtained from the Pasteur Institute (Algiers, Algeria). Rats were housed in clean polyethylene cages $(58 \times 38 \times 19 \mathrm{~cm}), 7$ rats per cage, and kept under standard conditions of temperature $\left(25 \pm 2^{\circ} \mathrm{C}\right)$, humidity $(65 \pm 5 \%)$ with a photoperiod. 12 hours of light and 12 hours of darkness. The rats were fed on commercial food and tap water ad libitum. Procedures for the care and handling of animals were following applicable international laws and policies (NIH Publication No. 85-23, 1985, revised 1996).

\subsection{Experimental study}

After an adaptation period, we chose 21 male Wistar rats according to the weight (200 $\pm 5 \mathrm{~g}$ ) which we separated into three experimental groups including one control group, 1 group fed with mineral water alone, and 1 group treated with fenugreek:

-Control ( $\mathrm{T}) \mathrm{n}=7$;

-Group force-fed with aqueous extract of fenugreek (F) $n=7$; -Group fed with mineral water alone $(G) n=7$;

Rats were identified by numbering at the tail with a permanent color marker.

\subsection{Animal treatment}


The administration of the water and the aqueous extract of the fenugreek seeds were carried out orally by the force-feeding method, which was carried out at 8:30 a.m. daily for 30 days in the rats of the batches $(G)$ and $(F)$.

\subsection{The aqueous extract of fenugreek seeds}

The aqueous extract of fenugreek was prepared by the infusion process. $250 \mathrm{~g}$ of fenugreek seeds were immersed in a liter (1L) of mineral water brought to a boil and kept at heat for five minutes $(5 \mathrm{~min})$. The extract is stored in the refrigerator until use (Harchane et al 2012).

\subsection{Body weight gain}

Using a digital scale, the weight of the rats of the three groups was taken daily from the first day (D1) until the last day of the experiment (D30).

\subsection{Neurobehavioral tests}

Innate anxious behavior is a fundamental component of the general behavior of rodents. It manifests itself in the attitude of the animal to be afraid when it is placed, without previous experience, in an unprotected environment. This behavior can be evaluated using validated experimental devices, the most widely used of which are the Elevated Plus Maze, the Light/Dark Box (LDB), and others. In this study, these tests were carried out at the end of the experiment.

\subsection{Elevated Plus Maze (EPM)}

The elevated plus maze is used to measure the degree of anxiety in rodents. (Handley and Mithany 1984) The device consists of an elevated and crossed maze with two open arms $(50 \mathrm{~cm} \times 10 \mathrm{~cm})$ and two closed arms $(50 \mathrm{~cm} \times 10 \mathrm{~cm} \times 45 \mathrm{~cm})$. The device is located at a height of $50 \mathrm{~cm}$ above the ground. (Patin et al 2005) this test is carried out for 5 min by placing the animal in the central area facing the open arms. Since the rat is afraid of empty and high spaces; his exploration with open arms indicates less anxious behavior. The more the animal is located in the closed arms, the more its behavior is designated as anxious. (Pellow et al 1985; Toumi 2014). At the end of this test, the following parameters are measured: - The time spent in open arms and the time spent in closed arms.
- The number of entries in closed arms and the number of entries in open arms.

\subsection{Light/Dark Box test (LDB)}

The LDB test is applied in that the rat naturally prefers dark places while avoiding well-lit ones. This ethological behavior is used to estimate the degree of anxiety in the animal. (Arrant et al 2013) The test is done in the OF device after dividing the floor into two compartments: one of them (the dark compartment) has been painted in black and lit by a dim red lamp, and the other (the clear compartment) was left transparent and lit by a bright white lamp. An opening acting as a door has been created between the two compartments, which allows the animal to move freely from one compartment to another. At the start of the test, the rat was placed in a clear compartment and its behavioral activities are recorded for 5 minutes.

\subsection{Statistical analysis}

All results were expressed as the mean \pm standard deviation $(M \pm S D)$. Statistical calculations were performed using GraphPad Prism software version 5.00 (Trial), March 12, 2007, except for body weights we used XLSTAT Launcher software (version 17.0.0.0) the comparison between the different groups was performed using Student's t-test. The differences were considered to be:

-Not significant when $(P>0.05)$;

-Significant when $(P \leq 0.05)$;

-Highly significant when $(P \leq 0.01)$;

-Very highly significant when $(P \leq 0.001)$. With $P$ : the significance level.

\section{Results}

\subsection{Bodyweight gain}

The weight of the control rats $(T)$ remained almost constant throughout the experiment. The treated group $(F)$ shows a highly significant increase in weight $(P \leq 0.01)$ compared to the control group (T). On the other hand, our results show a very highly significant decrease $(P \leq 0.001)$ in body weight in the group $(\mathrm{G})$ compared to the controls.

Table 1 Bodyweight changes in control rats $(T)$, rats treated with fenugreek $(F)$, and rats fed with water alone (G) during the experiment. The results are expressed as the mean $\pm \operatorname{SEM}(n=7)$.

\begin{tabular}{cccc}
\hline \multicolumn{3}{c}{ Weight (g) } \\
\hline Days & Group (T) & Group (G) & Group (F) \\
\hline D1 & $200.4 \pm 1.325$ & $200.0 \pm 1.195$ & $198.9 \pm 0.9619$ \\
D15 & $206.1 \pm 1.010$ & $205.1 \pm 0.8845$ & $211.7 \pm 0.5654$ \\
D10 & $211.4 \pm 1.066$ & $210.4 \pm 0.9221$ & $229.4 \pm 0.5281$ \\
D15 & $217.6 \pm 1.066$ & $216.4 \pm 1.020$ & $248.0 \pm 0.4364$ \\
D20 & $223.4 \pm 1.066$ & $222.1 \pm 0.9368$ & $276.1 \pm 0.6335$ \\
D25 & $229.3 \pm 0.8081$ & $227.9 \pm 1.010$ & $308.1 \pm 0.4592$ \\
D30 & $234.6 \pm 0.8411$ & $233.3 \pm 0.8650$ & $327.1 \pm 0.6701$ \\
\hline
\end{tabular}




\subsection{Blood sugar levels}

Our results show a very highly significant reduction ( $P$ $\leq 0.001$ ) in fasting blood glucose in the group (F) compared to control rats and a highly significant reduction $(P \leq 0.01)$ in blood glucose in the group (F) compared to in group (G) as well as a significant decrease $(P \leq 0.05)$ in blood glucose in the group $(\mathrm{G})$ compared to control rats (Figure 1 ).

Glycemia Evolution (g/l)

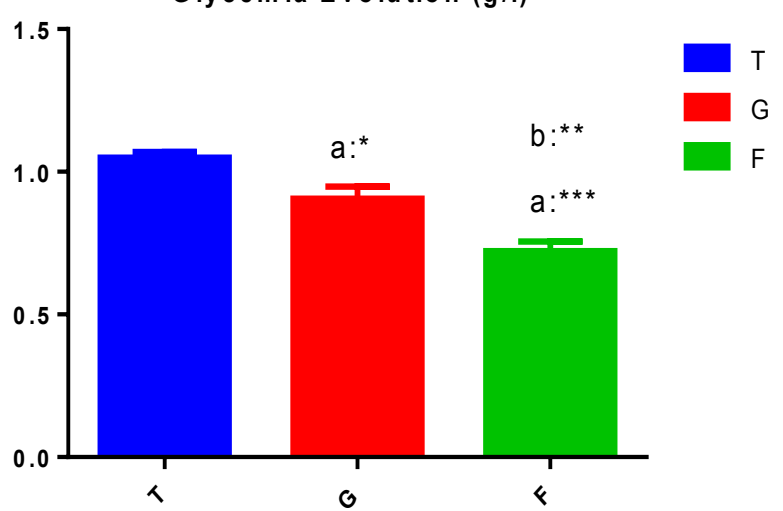

Figure 1 Variation in blood glucose $(g / l)$ in control rats $(T)$, rats treatedwithfenugreek (F) and rats fedwith water alone $(\mathrm{G})$. The results are expressed as Mean \pm SEM $(n=7)$. (a: comparison vs. T), (b: comparison vs. G). $P>0.05 ;{ }^{*} P<0.05 ;{ }^{* *} P<0.01 ;{ }^{* *} P<$ 0.001

\subsection{Change in HDL-cholesterol (HDL-C)}

Our results show an average normal level of HDL cholesterol equal to $0.3729 \mathrm{~g} / \mathrm{l}$ in the control group. In the group treated with fenugreek (F), the results show a significant increase $(P \leq 0.05)$ compared to the control rats and a non-significant increase $(P>0.05)$ in the group (G) compared to the batch (T) (Figure 3).

\subsection{Change in total cholesterol}

Our results show a highly significant reduction $(P \leq$ 0.01 ) in the total cholesterol level in the group treated with fenugreek $(F)$ compared to the control rats and a significant reduction $(P \leq 0.05)$ in the group $(\mathrm{G})$ compared to the group (T) (Figure 2).

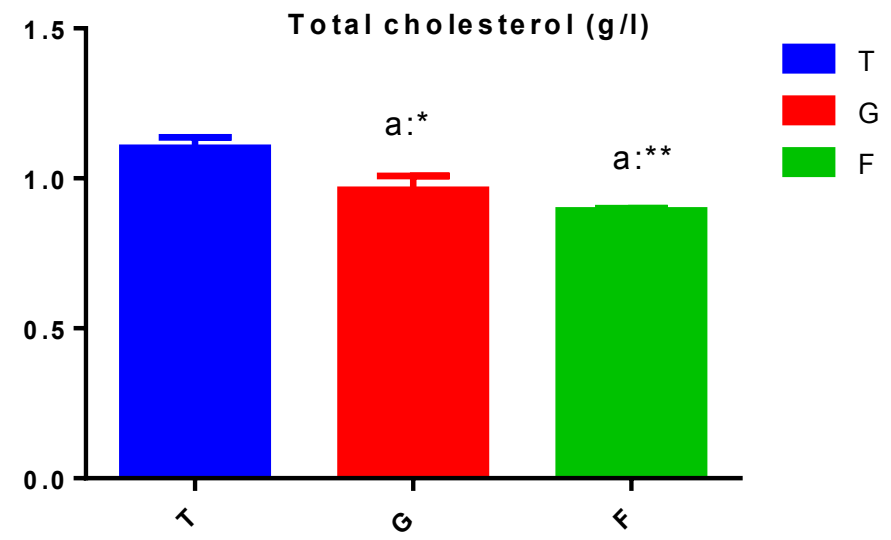

Figure 2 Change in total cholesterol $(\mathrm{g} / \mathrm{l})$ in control rats $(\mathrm{T})$, rats treated with fenugreek $(F)$ and rats fed only water $(G)$. The results are expressed as Mean \pm SEM $(\mathrm{n}=7)$ (a: comparison vs T). $P>0.05{ }^{*} P<$ $0.05{ }^{* *} p<0.01 ;{ }^{* * *} p<0.001$

\subsection{Change in LDL cholesterol levels}

According to the means of the LDL-c levels presented in the (Figure 4), measured in the rats of the three groups, we found in the group treated with fenugreek, a decrease compared to the control rats, this reduction is highly significant $(P \leq 0.01)$ thus a significant decrease $(P \leq 0.05)$ in the group $(G)$ compared to group $(T)$.
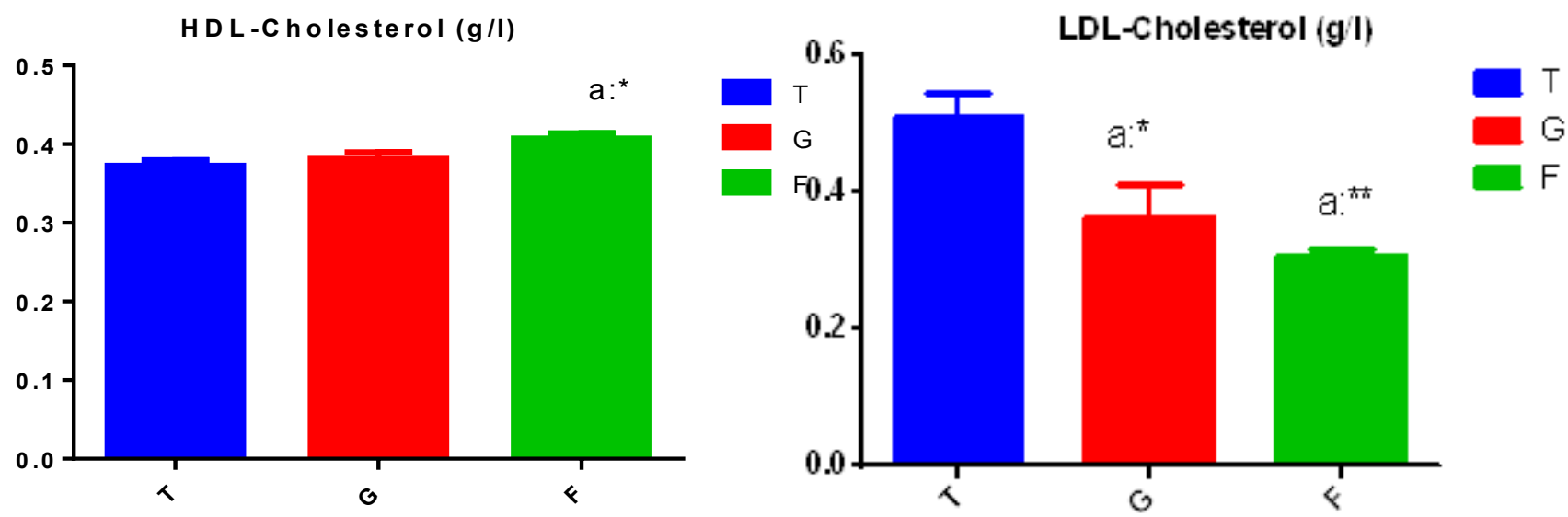

Figure 3 Variation in HDL cholesterol $(\mathrm{g} / \mathrm{l})$ in control rats $(\mathrm{T})$, rats treated with fenugreek $(F)$ and rats fed with water alone $(G)$. The results are expressed as Mean $\pm \operatorname{SEM}(n=7)$. (A: comparison vs. T). $P>0.05 ;{ }^{*} P<0.05 ;{ }^{*} P<0.01 ; * * * P<0.001$

Figure 4 Change in LDL cholesterol $(\mathrm{g} / \mathrm{l})$ in control rats $(T)$, rats treated with fenugreek (F) and rats fed with water alone $(G)$. The results are expressed as Mean \pm SEM $(\mathrm{n}=7)$ (a: comparison vs. T). $P>0.05 ;^{*} P<$ $0.05 ;{ }^{* *} p<0.01 ;{ }^{* * *} p<0.001$ 


\subsection{Variation in triglycerides}

Our results show a very highly significant decrease $(P$ $\leq 0.001$ ) of the group (F) compared to the control rats (T) and compared to the group (G) (Figure 5).

\subsection{Variation of neurobehavioral test parameters}

The group of control $(T)$ and treated $(F)$ and $(G)$ rats were subjected to the elevated plus maze (EPM) test on the last day of the experiment (day 30). From the results of the figure, we notice that the group of treated male rats (F) shows a very highly significant decrease $(P \leq 0.001)$ in the time spent in open arms compared to the controls $(T)$ with a very highly significant compared to group (G). Group (G) shows a very highly significant decrease $(P \leq 0.001)$ in the time spent in open arms per second (s) compared to group (T).
For the time spent in the closed arms of the labyrinth, our results show a very highly significant increase $(P \leq 0.001)$ in the group $(G)$ compared to the controls, concerning the group (F), (Figure 6) shows a very highly significant increase $(p \leq 0.001)$ compared to controls and a very highly significant decrease compared to the group (G). Regarding the number of entries into open arms, there is a very highly significant $(P$ $\leq 0.001$ ) in the group (G) compared to controls $(\mathrm{T})$ and a highly significant increase $(P \leq 0.01)$ in the group (F) compared to group $(G)$.

For the number of entries in closed arms, there is a highly significant decrease $(p \leq 0.01)$ in the treated rats $(F)$ compared to the controls $(T)$ and a very highly significant decrease $(P \leq 0.001)$ in the rats of the group $(\mathrm{G})$ compared to the controls $(T)$.

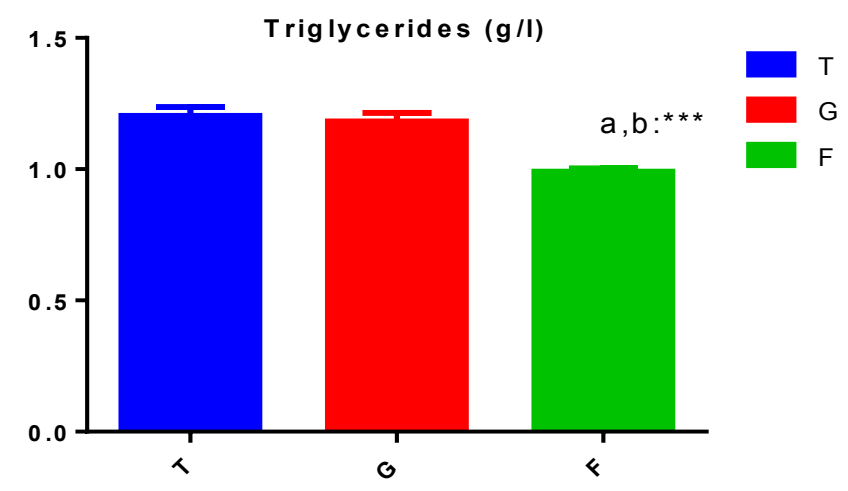

Figure 5 Change in triglyceride levels $(\mathrm{g} / \mathrm{l})$ in control rats $(\mathrm{T})$, rats treated with fenugreek $(\mathrm{F})$ and rats fed with water alone. The results are expressed as Mean \pm SEM $(\mathrm{n}=7)$. (a: comparison vs T; b: comparison vs G). $P>0.05 ;{ }^{*} P<0.05 ;{ }^{* *} P<0.01 ;{ }^{* * *} P<0.001$

\subsection{Variation of light/dark box test parameters}

From our results in Figure 7 , which shows the variations in the parameters of the light/dark box, we notice that the group of treated male rats (F) showed a very highly significant increase $(p \leq 0.001)$ in the time spent in the clear compartment compared to the group $(\mathrm{T})$ and $(\mathrm{G})$.

On the other hand, for the time spent in the dark compartment, the results demonstrate a very highly significant decrease $(P \leq 0.001)$ in the group $(F)$ compared to group $(\mathrm{G})$ and $(\mathrm{T})$ and a significant increase $(P \leq 0.001)$ in the group (G) compared to the control group (T).

\section{Discussion}

Lipids, hydrophobic molecules, include fatty acids, triglycerides, phospholipids, and cholesterol. Their main functions are energy carriers via triglycerides, components of cell membranes, precursors of steroid hormones via cholesterol, and lipid mediators. (Maqsood 2014).

Diabetes mellitus is a group of metabolic disorders characterized by hyperglycemia (Daisy et al 2013). In our study we confirmed that the aqueous extract of fenugreek seeds has a stimulating effect on body weight gain in male Wistar rats, these results are consistent with those obtained in humans and rats having received a diet rich in fenugreek powder, literatures (Petit et al 1995; Basch et al 2003; Vats et al 2004) and confirms the orexigenic role of fenugreek seeds.

Stimulation of appetite is obtained in rats after treatment with steroidal saponins extracted from fenugreek seeds. These saponins stimulate appetite in animals by altering the circadian rhythm of feeding behavior (Petit et al 1995).

Experimental studies in rats have shown that administration of $33,37.5$, or $333 \mathrm{mg} / \mathrm{kg}$ body weight per day of a fenugreek seed extract enriched with steroids enhances the activity of digestive enzymes and therefore a beneficial effect of fenugreek on digestion. A significant increase in food intake, bowel movements as well as motivation to eat has been noted (Meghwal and Goswami 2012).

Likewise, the high fiber content in fenugreek seed helps relieve the ailments observed during constipation (Who 2007; Meghwal and Goswami 2012) and other studies have highlighted a neuropeptide, NPY, a powerful hypothalamic orexigenic, mainly at the level of arcuate nuclei. Its level of 
production is subject to a circadian rhythm and it is regulated in particular by hormonal factors; it is inhibited by insulin and leptin and stimulated by ghrelin and glucocorticoids (Gourcerol et al 2006).

Besides, we noted a significant improvement in the lipid profile in the rats treated with the aqueous extract of fenugreek: - decrease in plasma triglycerides; hypocholesterolemic effect; - increase in the HDL-c fraction;
- reduction of LDL-c. These results confirm those found by Sowmya and Rajyalakshmi (Sowmya and Rajyalakshm 1999; Billaud and Adrian 2001), who have shown that the saponins of the fenugreek seed have physiological and functional properties, in particular a hypocholesterolemic effect linked to their emulsifying and hydrophobic character on the one hand and their role in increasing the biliary excretion of cholesterol from elsewhere (Stark and Madar 1993).

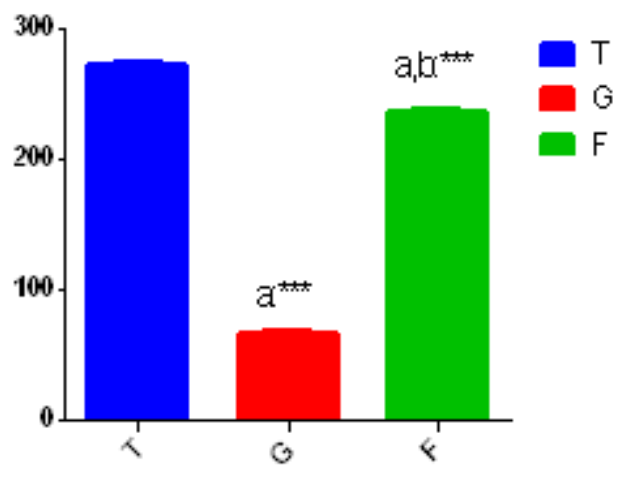

Tre spert in open ams inmleWstar rats (s)

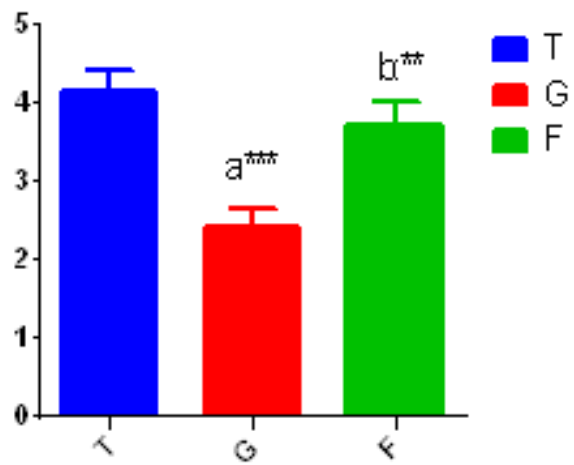

Nuber of etries into openams inmelehista rats

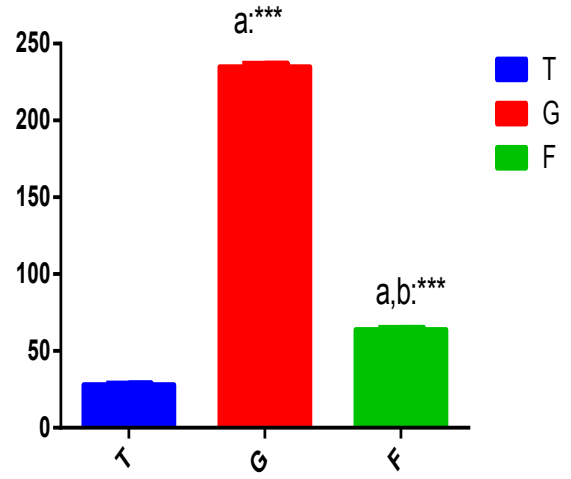

Time spent in closed arms in male Wistar rats $(\mathbf{s})$

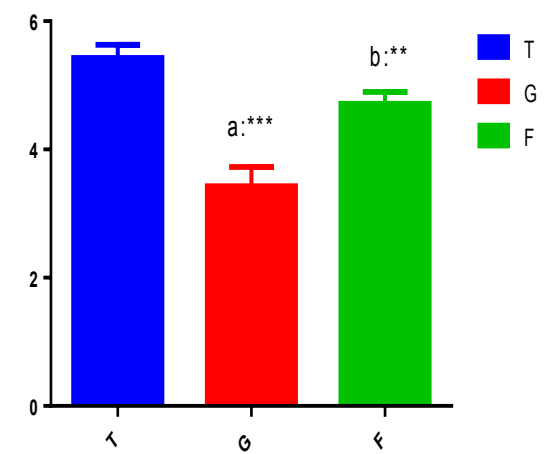

$\mathrm{Number}$ of entries into closed arms in $\mathrm{m}$ ale $\mathrm{W}$ istar rats

Figure 6 Variation in the parameters of the elevated plus maze (EPM) in the rats of groups (T), (G) and (F) during the experiment. The results are expressed as Mean $\pm \mathrm{SEM}(\mathrm{n}=7)$. (a: comparison vs $\mathrm{T}$; b: comparison vs $\mathrm{G}) . P>0.05 ; * P<0.05 ; * * P<0.01 ; * * * P<0.001$

Although the mechanism of action is not yet understood, it appears that internal steroidal fibers and saponins work with bile salts in the digestive tract. 4Hydroxy-isoleucine, an unusual amino acid isolated from fenugreek, has been tested in dyslipidemic hamsters. A significant decrease in plasma triglyceride levels by $33 \%$, total cholesterol by $22 \%$, and free fatty acids by $14 \%$, a $39 \%$ increase in the HDL cholesterol / total cholesterol ratio were observed (Braun and Cauhen 2010).

As for the decrease in the level plasma of triglycerides, it is thought to be due to soluble dietary fiber from fenugreek extract (Bainton et al 1992) Soluble fiber from fenugreek may lower triglycerides by decreasing unesterified fatty acids in rats.

Besides, our results clearly show a significant rise in HDL-c levels and a significant reduction in LDL-c levels, which would have an impact on reducing the risk of cardiovascular disease. This is in perfect agreement with the work of
(Tadigoppula et al 2005) that showed a 39\% increase in the HDL-c / total cholesterol (Arvill and Bodin 1995) ratio in hamsters treated with fenugreek powder and those (Hannan et al 2003).

In the present study, we observed a hypoglycemic effect of fenugreek on Wistar rats, which is consistent with the work of (Basu and Srichamroen 2010). Indeed, a hypoglycaemic and antidiabetic action has been demonstrated in animals. Studies have shown that Trigonella foenum-graecum, administered orally, produced a significant decrease in blood sugar in rats with Alexane-induced diabetes in a dose-dependent manner.

This action is mainly due to the presence of soluble fibers which decrease the activity of intestinal disaccharidase and the absorption of glucose. However, studies carried out in vitro and in vivo have shown that other constituents of the seed such as 4-hydroxy-isoleucine, galactomannan, and saponin, lower blood sugar and act in synergy to inhibit the 
absorption of glucose and promote functions pancreatic. (Vandenberg et al 2014).

Besides, there was also an increase in hepatic glycogenesis, glucose transport in adipocytes, and insulin action. Fenugreek, therefore, offers an alternative in the treatment and prevention of diabetes and its complications.

In this work, we tried to show the effect of fenugreek as a treatment for anxiety caused by forced feeding in Wistar rats, indeed, the results of neurobehavioural tests such as the elevated plus maze test (EPM) and light/dark box test (LDB), confirm this. (Brown et al 2000).

Regarding the test (EPM), the more the animal is located in the closed arms, the more its behavior is designated as anxious. (Kouadria et al 2020). We found that the rats of the group $(G)$ subjected to oral gavage of water alone spent more time with closed arms and less time in open arms compared to batch (F) and batch (T) respectively this means that batch $(\mathrm{G})$ is more anxious than batch $(\mathrm{F})$ the latter is more anxious than the control group $(\mathrm{T})$. These results are confirmed by those of the test (LDB) in which the rats of the group $(G)$ spend much more time in the dark compartment and less time in the light compartment in comparison with the group (F) which in turn spends less. As long as the group (T). (Djemli et al 2015; Mohamed Kouadria et al 2020).

The literature provided shows that force-feeding causes a rapid and pronounced stress reaction. Activation of the hypothalamic-pituitary-adrenal axis has been demonstrated in mice by increased fecal excretion of corticosterone, and in rats by increased blood pressure and heart rate (Kouadria et al 2019; Mohamed Kouadria et al 2020).

Some studies indicate that cardiovascular effects occur even when a small volume of fluid is given (contradicting the notion of excessive volume stress) and persist for at least 1 hour after force-feeding. Stress-induced physiological, metabolic (related in particular to the impact on enzymatic detoxification systems), endocrine, and behavioral changes are likely to interfere with the effects of the test substance. (Patricia et al 2012; Djemli et al 2015; Kouadria et al 2019; Kouadria et al 2020).

Although specific materials, such as oily vehicles, and high dose volumes (eg, $40 \mathrm{mg} / \mathrm{kg}$ ) can induce physiological responses in rats after force-feeding (Brown et al 2000) Orogastric gavage with aqueous materials induces adverse effects chronic stress in rats, deterioration of animal welfare is unknown (Patricia et al 2012).

Force-feeding can lead to complications such as the accidental introduction of fluid into the trachea and lungs, hepatic apoptosis, gastroesophageal reflux disease, chronic inflammation, bleeding, and weight loss. Some reports show a morbidity and mortality rate exceeding 50 \% (Vandenberg et al 2014).
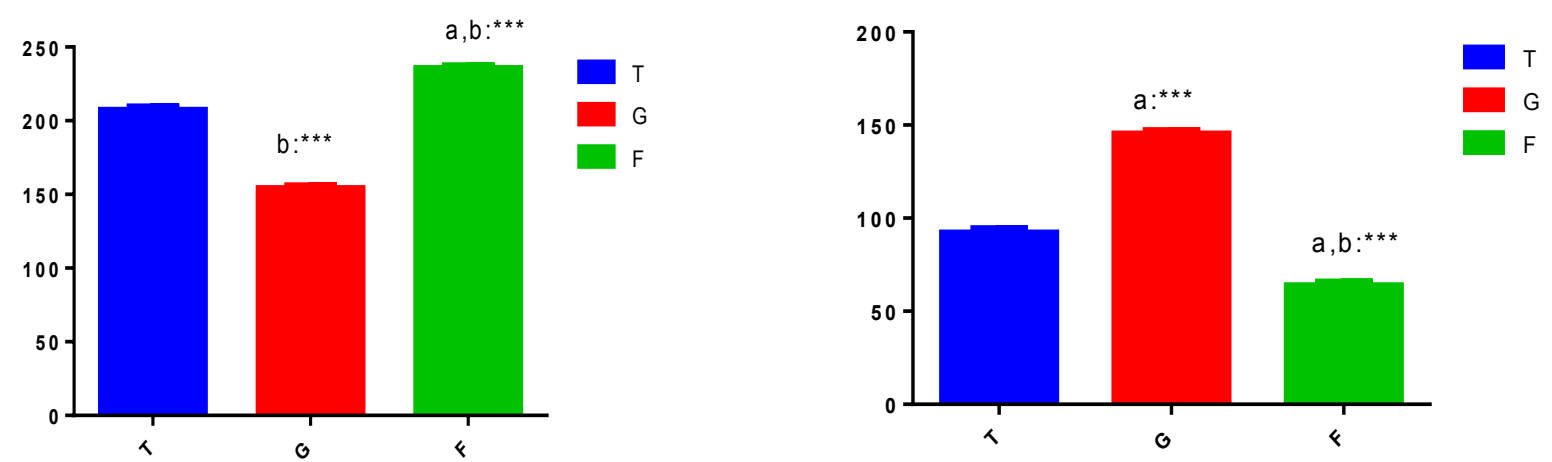

Time spent in the clear compartment by male W istar rats (s) Time spent in the dark compartment by male Wistar rats (s)

Figure 7 Variation of the parameters of the light/dark box test in rats during experimentation. The results are expressed as Mean \pm SEM ( $\mathrm{n}=7$ ). (a: comparison vs T; b: comparison vs G). $P>0.05 ; * P<0.05 ; * * P<0.01 ; * * * P<0.001$

\section{Conclusions}

Finally, our results show a remarkable loss in body weight at the group $(\mathrm{G})$ level compared to the other groups in the experiment, which explains why the force-feeding technique causes weight loss. Thus, we can affirm that the aqueous extract of fenugreek seeds, Trigonella foenumgraecum, thanks to its chemical compounds, therefore proves to be of great food value and has multiple phytotherapeutic virtues. Although in many countries many of the traditional medicinal uses of fenugreek seeds still feature, current research needs to focus on the mechanisms of action of these products.

\section{Acknowledgments}

We wish to acknowledge Pr. Abdelkrim Tahraoui head of Applied Neuroendocrinology laboratory Department of Biology University Badji Mokhtar, Annaba, Algeria, for his help support, and encouragement.

\section{Conflict of Interest}

The authors declare no conflict of interest.

\section{Funding}

This research did not receive any financial support. 


\section{References}

Arrant AE, Jemal H, Kuhn CM (2013) Adolescent Male Rats Less Sensitive ThanAdults To The Anxiogenic And Serotonin- Releasing Effects Of Fenfluramine. Neuropharmacology 65:213-222.

Arvill A, Bodin L (1995) Effect of short-term ingestion of konjac glucomannan on serum cholesterol in healthy men. Am J Clin Nutr 61:585-590.

Bainton D, Miller NE, Bolton CH, Yarnell JWG, Sweetnam PM, Bake IA, Lewis $B$, Elwood PC (1992) Plasma triglyceride and high-density lipoprotein cholesterol as predictors of ischaemic heart disease in British men. Heart BMJ journals 68:60-66.

Basch E, Ulbricht C, Kuo G, Szapary P, Smith M (2003) Therapeutic Applications of Fenugreek. Alternat Med Rev 8:20-27.

Basu TK, Srichamroen A (2010) Health benefits of Fenugreek (Trigonella foenum-graecum, Leguminosae) bioactive foods in promoting health: Fruits and Vegetables. Elsevier. 425-35.

Billaud C, Adrian J (2001) Le fenugrec: composition, valeur nutritionelle et physiologique = Fenugreek: composition, nutritional value and physiologicalproperties. Sci Aliments 21:320-326.

Braun L, Cohen M. (2010) Introduction to herbal medicine. Herbs and Natural Supplements. 1, 3rd ed.

Brown AP, Dinger N, Levine BS (2000) Stress produced by gavage administration in the rat. Contemp Top Lab Anim Sci 39:17-21.

Daisy P, Feri G, Jeeva K (2013) Hypolipidemic And Hepatoprotrctive Effects Of Cassia Auriculata Linn Barck Extracts On Streptozotocin-Induced Diabetics In Male Wistar Albinos Rats. Asian J Pharm Clin Res 6:43-48.

Djemli S, Fraia A, Frih H, Bachir A, Zaafour M and Djenidi R (2015) Neurobehavioral Effects of Dexamethasone (Inhibition of Adrenal Axis) in Male Mice Mus musculus. Global Veterinaria 15:545-553.

Ghourri M, Zidane L, Douira A (2013). Usage des plantes médicinales dans le traitement du Diabète Au Sahara marocain (Tan-Tan). Journal of Animal \& Plant Sciences 17:2388-2411.

Gourcerol G, Ducrotté P, Vandry H, Jégon S (2006) Intégration Des Signaux Digestifs Par L'hypothalamus, Mécanismes Et Implications Thérapeutiques. Neurologie 19:42-47.

Hamden K, Keskes H, Belhadj S, Mnafgui K, Feki A, Allouch N (2011) Inhibitory potential of omega-3 fatty and fenugreek essential oil on key enzymes of carbohydrate-digestion and hypertension in diabetes rats. Health and Disease10:222-226.

Handley S L, Mithani S (1984) Effects of alpha-adrenoceptor agonists and antagonists in a Maze exploration model of 'fear'-motivated behaviour. Naunyn-Schmiedeberg's archives of pharmacology 327:1-5.

Hannan J, Rokeya B, Faruque O (2003) Effect Of Soluble Dietary Fibre Fraction Of Trigonella foenum-graecum On Glycemic, Insulinemic, Lipidemic And Platelet Aggregation Status Of Type 2 Diabetic Model Rats. J Ethnopharmacol 73-88.

Harchane H, El Addas H, Amsaguine S, El Amrani N, Radallah D (2012) Effects I'extrait aqueux des graines du fenugrec (Trigonella foenum-graecum L.) sur I'amélioration du profil et la prise de poids chez le rat. Springer-verlag France, pp 1-6.

Ionescu AM, Roman GV (2013) Research on biology, productivity and yield quality of Trigonella foenumgraecum L. species (fenugreek) in the central part of the south Romanian plain. Scientific papers. Series A. Agronomy. LVI.
M Kouadria, S Djemli, A Tahraoui (2019) The protective effect of Zinc and Magnesium against subchronic Cadmium toxicity in Wistar rats (Biochemical and neurobehavioral effects). Asian Journal of Pharmaceutical and Clinical Research 12:217-225.

Maqsood Z (2014) Prescription des statines en soins primairesd'après les données scientifiques actuelles.

Meghwal M, Goswami TK (2012) A Review on the functional properties, Nutritional Content, Medicinal Utilization, and Potential Application of Fenugreek. J Food ProcessTechnol 3:181-184.

Kouadria M, Djemli S, Tahraoui A (2020) Hepatoprotective effect of zinc and magnesium against subchronic cadmium toxicity on biochemical, histopathological and neurobehavioral parameters in Wistar rats. Journal of Animal Behaviour and Biometeorology 8:63-73.

Moradikor N, Didarshetaban MB, Saeid Pour HR (2013) Fenugreek (Trigonella foenum-graecum L.) as a valuable medicinal plant. International Journal of Advanced Biological and Biomedical Research 1:922-931.

Patin V, Lord B, Vincent A, Caston J (2005) Effects Of Prenatal Stress On Anxiety And Social Interactions In Adults Rats. Dev Brain Res 160:265-274.

Patricia VT, Elizabeth V, Janet SN, Jelena O, Francesco L (2012) Oral Gavage in Rats: Animal Welfare Evaluation. JAALAS 51:25-30.

Pellow S, Chopin P, File SE, Briley M (1985) Validation of Open: Closed Arm Entries in an Elevated Plus Maze as a measure of Anxiety in the Rat. J Neurosci Methods 33:134-140.

Petit PR, Sauvaire YD, Hilaire-Buys DM (1995) Steroid Saponins from Fenugrec Seeds: Extraction, Purification And Plasma Cholesterol. Steroids 60:674-680

Sowmya P, Rajyalakshm P (1999) Hypocholesterolemic effect Of Germinated Fenugreek Seeds in human subjects. Plant Foods For Human Nutr 53:359365.

Stark A, Madar Z (1993) The Effect of an Ethanol Extract Derived from Fenugreek (Trigonella foenum-graecum) On Bile Acid Absorption And Cholesterol Levels In Rats. Br J Nutr 69:277-287.

Tadigoppula N, Anju P, Tanvir K, Rashmi S, Geetika B, Ramesh C (2005) 4 Hydroxyisoleucin And Unusual Amino Acid As Antidyslipidimic And Antihyperglycemic Agent. Bioorg Med Chem Lett 16:293-296.

Talip C, Munevver NP, Hasn A, Murat E, ZekiAytac (2011) Comparative seed morphology of Trigonella L. Species (Leguminosae) in Turkey. African Journal of Agricultural Research 7:509-522.

Toumi ML (2014) Impact Du Stress Prénatal Anxio-Oxydatif Sur Les Capacités Cognitives Maternelles Et L'Emotivité De La Progéniture Chez Des Rattes Traitées A La Quercétine. Thèse de Doctorat.

Vandenberg LN, Welshons WV, VomSaal FS, Toutain PL, Myers JP (2014) Should oral gavage be abandoned in toxicitytesting of endocrine disruptors? Environmental Health 13-46.

Vats V, Yadaw SP, Grover JK (2004) Ethanolic Extract of Ocimum Sanctum Leaves Partially Attenuates Streptozotocin-Induced Alterations In Glycogen Content And Carbohydrate Metabolism In Rats. J Ethnopharmacol 90:155160.

WHO, Monographs On Selected Medicinal Plants (2007) WHO Press, Geneva. Vol 3. 